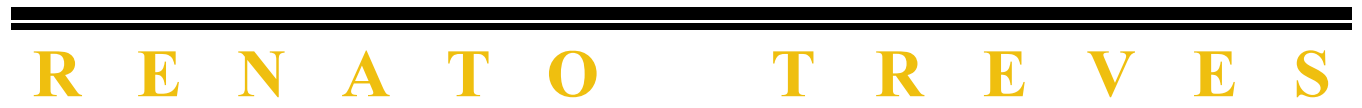




\section{RENATO TREVES (1907-1992)}

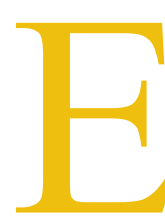

ra un hombre bueno y con las ideas claras. ¿Era, digo así, en irremediable pasado? No acabo de hacerme a la idea, cuando escribo estas páginas que me pide Manuel Atienza para «Doxa», de que de verdad el gran amigo y querido maestro Renato Treves esté ya muerto. Me parece que no es así, que ha sido únicamente un mal sueño, que sigue bien en Milán haciendo su vida y sus trabajos y que, aunque hace tiempo que no le veo, ni me escribe, ni sé de él, es sólo que últimamente ha estado muy ocupado y que va a llamarme por teléfono en cualquier momento para hablarme de proyectos, papeles, viajes, revistas, gentes, como solía hacerlo: con frecuencia en los fines de semana y por las mañanas... muy, muy temprano. ¡El viejo montañero, austero, deportista y madrugador! Una vez tuve que hacerle ver, con sumo tacto y delicadeza (a él que era siempre tan educado y prudente), que sería mejor que llamara un poco más tarde, que aquí algunos viernes o sábados trasnochábamos más de la cuenta...

Pero quien de hecho ahora me llama es Atienza para devolverme a la dura realidad, para instarme a que me ponga a escribir estas notas en memoria de aquél. Así lo hago, obediente y apesadumbrado.

Han sido largos años de intensa relación personal, de profundo afecto y amistad, y de frecuente relación intelectual -libros, ideas, encuentros, debates- con el profesor Renato Treves. Pienso que al hilo de todo ese tiempo, su obra y magisterio han estado siempre muy presentes tanto en mis cursos universitarios como en la mayor parte de mis publicaciones: en ellas, junto a la influencia implícita y junto a análisis más distantes y objetivos, ha ido ya quedando expreso reconocimiento por mi parte del aprecio y consideración muy positiva de sus trabajos, sin perjuicio de mutuas discrepancias y observaciones críticas que enriquecían y fortalecían por lo demás esa nuestra relación personal e intelectual. Así, pues, a esos escritos míos reenvío aquí para un más amplio conocimiento 
de su filosofía y su sociología, así como para unos u otros temas más concretos y / o para enfoques más académicos y sistemáticos que no tendrían ahora adecuada cabida, ni (todos) siquiera oportuna mención, en estas informales páginas finales de homenaje y recuerdo al maestro y amigo, sí, por desgracia irremediablemente desaparecido ${ }^{1}$.

Conocí personalmente a Renato Treves en Madrid, en 1966, en la sede del «Centro de Enseñanza e Investigación» (CEISA), institución libre que, para la introducción de nuevos estudios, orientaciones y metodologías, había tenido que crearse fuera de la Universidad a la vista de (y a pesar de) las dificultades oficiales de la época, sede que lo era también de su «Escuela de Ciencias Sociales» donde como profesores de Sociología del Derecho estábamos encargados Luis García San Miguel y el autor de estas líneas. Yo lo conocía sólo «de leídas» de sus libros (por ejemplo, Sociología y Filosofía social, de 1941, o Derecho $y$ cultura, de 1947) desde mis tiempos de estudiante y joven graduado trabajando con Joaquín Ruiz Giménez en la Universidad de Salamanca y después -en mis años de doctorado en Bolonia- por sus trabajos sobre el Estado de Derecho y la espuria utilización que de él se había pretendido hacer en los Estados totalitarios. En ese 1966, Renato Treves que había sido nombrado en 1962 Vicepresidente de la «International Sociological Association» (lo sería hasta el mismo 1966) y, dentro de ella, Presidente del «Research Committee on Sociology of Law» (hasta 1974), aceptó nuestra invitación para pronunciar un ciclo de conferencias en dicha «Escuela» contribuyendo así de manera muy decisiva a incrementar entre nosotros el interés por la Sociología del Derecho y avalando con su palabra y su presencia personal, y con la representación internacional que implicaba, las tareas y propósitos de ese «Centro» que, a pesar de todo, habría de ser clausurado por orden gubernativa -jesos eran los tiempos!- no muchos meses después ${ }^{2}$.

${ }^{1}$ El estudio e influencia de su obra, en los sucesivos momentos cronológicos, está con un carácter más amplio y general primeramente en buena parte de mi libro Sociología y Filosofía del Derecho, Madrid, Taurus, 1971 y ediciones posteriores; después, con propósitos más específicos, en el trabajo sobre «El juez y la sociedad: La Sociología jurídica y la Sociología judicial en la obra de Renato Treves», reconstruido como capítulo segundo de mi Legalidades-Legitimidad en el socialismo democrático, Madrid, Civitas, 1978; finalmente, resaltando también sus posiciones básicas, en el artículo (a propósito de la publicación de su Sociologia del Diritto) aparecido, bajo el título Iluminismo crítico y Sociología del Derecho, en la revista «Saber / Leer», núm. 12, Madrid, febrero de 1988.

${ }^{2}$ Más datos sobre nombres y vicisitudes del «Centro de Enseñanza e Investigación» y su «Escuela de Ciencias Sociales», inspirada ésta y aquél de manera muy principal por los profesores Tierno Galván y Aranguren -expulsados por 
Esa visita de Treves y esos días de trabajo en Madrid, además de dar origen a muy gratas y, en algunos casos como el mío, a perdurables amistades personales y a fructíferas relaciones científicas, fueron también para él oportuna y emotiva ocasión -era su primer viaje a España- para tomar contacto en el interior con profesores y ámbitos culturales y políticos críticos y de oposición al régimen franquista. Y, desde ahí, para reenlazar evocando su lejano pasado con los años de exilio en Argentina (1938-1947) donde conoció y había, asimismo, entablado buena relación con intelectuales republicanos españoles (Luis Jiménez de Asúa, Lorenzo Luzurriaga, Jesús Prados Arrarte, Francisco Ayala, entre otros) que al igual que no pocos italianos (R. Mondolfo, los hermanos Terracini o G. Turín, por reducirme a los que coincidieron allí más con él) habían tenido que abandonar sus respectivos países perseguidos por los regímenes totalitarios de signo fascista en ellos implantados ${ }^{3}$.

Desde entonces, y cada vez más en los frecuentes contactos de los últimos tiempos, la cultura y la filosofía española (Ortega y Gasset y los exiliados casi desde el principio, Fernando de los Ríos después, con el pensamiento de oposición a la dictadura en esa misma década de los sesenta-setenta) han encontrado en Renato Treves muy receptiva acogida al unísono de su sincera preocupación y sus constantes esfuerzos y apoyos en pro de la democracia para nuestro país. Recuerdo en este sentido como especialmente feliz y esperanzado su primer retorno a España tras

entonces de la Universidad oficial- y dirigida la segunda por J.A. Maravall, J.L. Sampedro y A. Truyol Serra, con gestión y coordinación general de J. Vidal Beneyto, pueden localizarse en mi Sociología y Filosofía del Derecho, cit., 2. ed. de 1980, págs. 170 y 171.

${ }^{3}$ De esos años en Argentina -allí conoció Renato Treves a quien después sería su esposa Fiamma Lattes, también de familia italiana de exiliados-, en lo que a relaciones intelectuales se refiere ha quedado, entre otros, el recuerdo de la amistosa y muy interesante polémica que sobre antifascismo, liberalismo y democracia mantuvieron entonces Francisco Ayala (más pesimista hacia el liberalismo con la experiencia republicana española detrás) y Renato Treves (insistiendo más en el positivo carácter antifascista de los intelectuales liberales), siendo después publicados ambos textos en un pequeño volumen, Una doble experiencia política: España e Italia, Colegio de México, 1944. Treves volvió sobre esa antigua polémica en 1987-1988, Antifascismo italiano e spagnolo nell'esilio argentino. Un dibattito e altri ricordi («Nuova Antologia», Florencia, 1988), con recuerdos también para su amigo Diego Abad de Santillán; y Francisco Ayala se hizo eco de ella, Evocación de un viejo debate (en «El País», 25 de febrero de 1988), con consideraciones que conservan validez desde ayer y para hoy. Ambos textos de 1988 pueden localizarse ahora en el libro de recuerdos y encuentros de Treves a que se hace aquí referencia en la nota siguiente. 
la muerte de Franco, a Asturias en concreto, en marzo de 1976, respondiendo a la invitación que le habíamos cursado para pronunciar dos conferencias en la Universidad de Oviedo donde yo era entonces catedrático con Manuel Atienza, joven ayudante, como eficiente programador de la visita ${ }^{4}$.

La filosofía y la sociología crítica de Renato Treves, su más propia y personal actitud intelectual construida desde el punto de encuentro de la tolerancia y el compromiso, no fue, ni pretendió ser nunca -como estamos viendo- de neutra, indiferenciada e indiferente «neutralidad». La realidad y la historia tampoco lo son: intereses, valores, apropiaciones, desigualdades, ideas, libertades están siempre allí en tensión y conflicto. El rigor intelectual y científico, imprescindibles, operan siempre en ese marco, para comprenderlo y para, además, hacer algo con él, transformarlo y / o conservarlo. Su «concepción del mundo» y en filosofía política su socialismo liberal -así se autodefinía él- si acaso estarían más cerca de lo que Unamuno, con mayor carga agonista hispánica, llamaba «alterutralidad»: con unos y con otros (el vasco también contra unos y contra otros) pero en todo caso, con crítica, uniéndolos y fundiéndolos; así ocurriría en Treves no con cualquier cosa sino justamente con el liberalismo y el socialismo. Nunca aparte, no «neuter», ni con unos ni con otros, elitistamente, por encima del bien y del mal, sino comprometiéndose y tomando posición: contra el fascismo, que le persiguió con sus leyes racistas, contra la intolerancia y contra todo totalitarismo, en defensa del pluralismo democrático en política y -compleja correlación gnoseológica- en su adhesión al relativismo y al perspectivismo,

${ }^{4}$ Aquellos primeros y posteriores perdurables contactos con la España democrática han sido recordados y resaltados por él mismo, en el marco general de su biografía y de sus relaciones con intelectuales italianos y extranjeros, en uno de sus últimos y más personales libros, Sociologia e socialismo. Ricordi e incontri, Milán, Franco Angeli, 1990, págs. 227 y ss (trad. cast. de Luis C. Aparicio y Rafael de Asís, Prólogo de Gregorio Peces Barba, Madrid, Centro de Estudios Constitucionales, 1991, págs. 273 y ss.). Esta obra, «casi un testamento espiritual», califica tras la muerte de Treves uno de sus principales discípulos, el profesor Vincenzo Ferrari (Un innovatore tra le norme, «Il Sole, 24 Hore», 14 de junio de 1992), verdadera «autobiografía cultural» -así titula su comentario a ella Giuseppe Gadda Conti en «Il Giornale», 17 de febrero de 1991-, proporciona en efecto observaciones e informaciones muy valiosas tanto para su vida privada como intelectual, ambas siempre en él íntima e indisolublemente trabadas; otro comentario interesante sobre dicha obra y la personalidad de su autor -destacando en él la sobriedad y en aquella el no rechazo de valores e ideas en el tratamiento de los hechos- es también el de Gaetano Pecora, In difesa della tolleranza, en «Il Mattino», 28 de enero de 1991. 
propugnando de siempre el espíritu crítico frente al espíritu dogmático en la ciencia y en la filosofía ${ }^{5}$.

J. Ortega y Gasset, precisamente resaltando en él su perspectivismo, R. Mondolfo por su «problematismo», dice Treves, como «intérprete liberal del marxismo», socialismo humanista que le conecta no sin diferencias con el menos marxista de Fernando de los Ríos en España, K. Mannheim como uno de los padres fundadores de la sociología del conocimiento, H. Heller y su concepción del Estado como Estado de Derecho construido desde el socialismo liberal y democrático, últimamente Wright Mills y su «imaginación sociológica» serían algunos de los coherentes inspiradores de su teoría del conocimiento, de su filosofía política y, en relación con ellas, de su prevalente posición desde un prioritario, necesario, énfasis en las investigaciones empíricas hacia el no menos necesario entronque en una sociología teórica y crítica. Su socialismo liberal se inspira de manera asimismo muy decidida en una firme tradición italiana que Treves vincula, entre otros, a Piero Gobetti, Gioele Solari, Alessandro Levi, el propio R. Mondolfo y, en polémica con éste, los hermanos Carlo y Nello Roselli ${ }^{6}$.

Por lo que se refiere más específica y profesionalmente al mundo jurídico -recordemos para el profano que Treves fue desde 1949 en la Universidad de Milán catedrático de Filosofía del Derecho y desde 1976 de Sociología del Derecho- puede,

${ }^{5}$ Spirito critico e spirito dogmatico, de 1954, es en efecto uno de los libros más representativos de su bibliografía. En su repercusión política, Vincenzo Ferrari habla con acierto de esa «tolerancia liberal, nunca separada de ese sentido profundo de igualitarismo que es propio de la idea socialista. Treves, en efecto -señala aquél- era un socialista liberal» (artículo citado en la nota anterior). Ténganse también en cuenta las observaciones críticas del profesor Uberto Searpelli (Il diritto dietro le lenti di un liberal-socialista, en «Il Sole, 24 Hore», 22 de marzo de 1987), en el sentido de que esas opciones valorativas y políticas más que «fruto de un estudio científico de la sociedad», como apuntaría un aquí casi cognoscitivista Treves, serían -dice- una «opción ética situada fuera de la ciencia»: yo, con todo, no escindiría tan dualistamente ciencia y ética en esa producción de los valores.

${ }^{6}$ Algunos de los ensayos de Treves sobre estos autores, Ortega, Mannheim, Heller, Mondolfo, Solari o Levi, precedidos de una introducción sobre «Libertad y socialismo en la emigración intelectual italiana y española», pueden encontrarse en su libro Libertá politica e veritá, Milán, Ed. di Comunitá, 1962; el sector italiano de ellos, con correcciones y alguna parte nueva, se publicó en la revista «Sistema», núm. 7, octubre de 1974, en traducción de Perfecto Andrés Ibáñez, El socialismo liberal en Italia: algunos capítulos de su historia (págs. 5-27). Para otros autores y momentos, incluidos tres capítulos sobre su íntimo amigo y compañero Norberto Bobbio desde esa misma perspectiva del socialismo liberal, reenvío a la ya citada «autobiografía cultural» de la nota 4 , Sociologia e socialismo. Ricordi e incontri. 
creo, decirse que los dos grandes pilares de su pensamiento han sido desde muy temprano, desde el principio, Kelsen para estrictamente la Teoría del Derecho y Weber para la Sociología del Derecho. Pero lo característico, y acertado, de su posición es que -a diferencia de lo que es bastante habitual- Treves insistirá en situar ambas posiciones en compatibilidad y mutua interrelación transformadora, con aportaciones sin duda decisivas para esa crítica mediación desde la filosofía jurídica, ética y política de Norberto Bobbio ${ }^{7}$.

Ha sido justamente Norberto Bobbio quien desde siempre más ha insistido en el mérito de Renato Treves como estudioso, traductor e introductor de Kelsen en la ciencia y filosofía jurídica italianas desde principios de los años treinta. Y ahora, después de la muerte de éste, el viejo amigo ha vuelto a evocarlo, en ese mismo 1992, uniendo desde el principio sus biografías -entonces con investigaciones teóricas diferentes- en aquellos ya lejanos tiempos: «Renato Treves y yo -escribe Bobbio-, ambos alumnos de Solari orientados al estudio de la filosofía del derecho alemana, nos habíamos repartido los campos: él estudiaría la Escuela de Marburgo, en la cual se había inspirado Kelsen, y yo la fenomenología, de la que habían aparecido por entonces los primeros intentos de extensión al mundo del derecho. Se publicaron -recuerda- en el mismo año (1934) su libro Il diritto come relazione. Saggio critico sul neokantismo contemporaneo, y el mío, L’indirizzo fenomenológico nella filosofia sociale e giuridica. Mientras que de Treves -subraya Bobbio- se puede hacer comenzar la

${ }^{7}$ Acerca de todo ello, sobre otros destacados autores (Gurvitch, Geiger, etc.), sobre las positivas evoluciones internas del propio Treves, insertando la investigación empírica en la Sociología crítica, sobre la configuración y contenido actual de ella y sobre otras muchas cuestiones de interés (la crítica al estructural-funcionalismo, por ejemplo) puede verse su obra básica Sociologia del

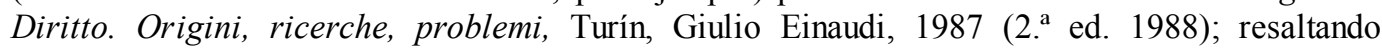
respectivamente la conexión de esa sociología crítica con el socialismo liberal y el «empeño civil del científico social», están las recensiones a este libro de Treves escritas por Manuel Calvo García («Anuario de Filosofia del Derecho», IV, 1987) y Luis C. Aparicio («Sistema», 82, enero de 1988); la muy cuidada versión castellana es de María José Añón, J. A. Pérez Lledó y Manuel Atienza, con detallada y rigurosa Nota Preliminar de este último en torno a esos cambios internos y evoluciones externas de su autor (Barcelona, Ariel, 1988). Precisamente también Manuel Atienza y Juan Ruiz Manero son los autores de la formativa e informativa Entrevista a Renato Treves (publicada en «Doxa», núm. 8, Universidad de Alicante, 1990) donde, además de darse un buen resumen de datos biográficos de aquél, se apuntan vías válidas para prolongar y / o debatir a fondo acerca de cuestiones que yo aquí no hago apenas sino que insinuar, como entre otras, por ejemplo, las aludidas antes (relativismo-cognoscitivismo) en relación con la nota 5 y después (formalismo-sociologismo) en relación con la nota 10 . 
eficaz difusión de Kelsen en Italia, si bien existiera ya algún escrito precedente, mis estudios sobre la fenomenología en la teoría del derecho no tuvieron continuación alguna. Yo mismo los abandoné bien pronto a la furia crítica y roedora de los ratones. Mi kelsenismo, por el cual -advierte aquél- soy con frecuencia considerado como uno de los mayores, si no el mayor responsable de la "kelsenitis" italiana, comenzó muchos años después. Como ha sido hecho notar, yo era entonces no tanto un nokelseniano cuanto un antikelseniano» ${ }^{8}$.

Me parece importante resaltar ese fondo, y trasfondo, kelseniano del pensamiento jurídico de Renato Treves compatible, como digo, con su Sociología del Derecho en la mejor tradición weberiana. Pero, sin desconocer para nada las autonomías propias y, a la vez, las influencias recíprocas entre los dos maestros italianos, habría -creo- que señalar que en estos puntos centrales Treves corrige bien la pureza autista de Kelsen (y del formalismo jurídico) precisamente desde Bobbio: quiero decir, desde, por de pronto, la inflexión que lleva éste a cabo complementando el análisis de la estructura con el de las implicaciones derivadas de la función o funciones del Derecho, cuestión en la que Treves, junto a otros sociólogos pasados y presentes, tiene muy en cuenta las importantes observaciones diferenciadoras de Vincenzo Ferrari ${ }^{9}$. No tendrá tampoco problemas insalvables para desde ahí coincidir con Bobbio en situar el fundamento de la validez jurídica en la eficacia empírica de la fuerza social y del poder político, más allá, por tanto, de las insuficiencias internas y externas de Ross y de las, además, probables ambigüedades últimas de Hart (sin perjuicio,

${ }^{8}$ Norberto Bobbio, Diritto e potere. Saggi su Kelsen, Nápoles, Edizioni Scientifiche Italiane, 1992 (Colección «Diritto e Cultura», dirigida por Agostino Carrino), pág. 5 de la «Prefazione» fechada el 5 de agosto de 1992 y que se abre con estas palabras de aquél: «Dedico este libro a la memoria de Renato Treves, con quien tuvieron inicio los estudios kelsenianos en Italia, fallecido el 31 de mayo de 1992 en los mismos días en que yo estaba terminando de preparar esta recopilación y durante los cuales la querida imagen de Renato ha estado siempre presente en mi mente». En la misma editorial y colección que este libro de Bobbio, y también con prólogo suyo, acaba de volver a publicarse, en 1993, la obra de Treves de 1934 a que en el texto transcrito se hacía por él referencia. En otros momentos de su larga y profunda amistad, Bobbio ha aprovechado bien para dar sincero testimonio de ella y de su alto aprecio por la obra de aquél: Il magistero di Renato Treves, texto jubilar publicado en «Nuova Antologia» (octubre-diciembre de 1984) es un buen ejemplo de ello; en trad. cast. de Alfonso Ruiz Miguel se publicó en «Sistema», núm. 73, julio de 1986.

${ }^{9}$ Vincenzo Ferrari, Funzioni del diritto. Saggio critico-ricostruttivo, Roma-Bari, Laterza $1987 ; 2^{\circ}$ ed., revisada y con nueva interesante nota preliminar,1989 (trad. cast. de María José Añón y Javier de Lucas Martín con muy útil y bien orientada Nota introductoria de este último, Madrid, Debate 1989). 
por supuesto, de los méritos y aportaciones reconocidos a ambos). En el otro, central, orden de cosas, el de la justificación ética del Derecho, la coincidencia de Treves con Bobbio en los valores fundamentales y en sus connotaciones políticas es, sin duda, casi absoluta y total, con reservas kelsenianas ante el cognoscitivismo que en buena parte se superan desde ese entronque social (criticado por Scarpelli) y un uso no reductivo-cientificista de la razón ${ }^{10}$.

Desde estas coordenadas es verdad, no obstante, que Treves, dedicado muy prioritariamente a la Sociología del Derecho -y ahí sus impulsos, investigaciones y aportaciones han sido decisivas- no se ha ocupado en igual medida y de manera expresa ni de algunos debates habituales en todos estos tiempos acerca de los problemas de la validez (Ciencia del Derecho), ni de todas las últimas teorías formuladas sobre la fundamentación ética (Filosofía del Derecho). A mi juicio, si no ha insistido en ello de forma más extensa y directa fue también porque en las líneas principales y básicas de una y de otra venía a coincidir casi plenamente con las que él (sin mimetismos acríticos) reconocía, junto a otros autores cercanos, en la filosofía jurídica de su admirado amigo del alma Norberto Bobbio. Como se ve, de algún modo continuó entre ambos, aunque con ciertos cambios de área y no sin interconexiones, aquella -por lo demás nunca deterministamente planificada- primera y antigua división de trabajo ${ }^{11}$.

${ }^{10}$ Para esa su antigua, profunda y crítica relación con el padre de la «teoría pura del Derecho», es del mayor interés el volumen conjunto Hans Kelsen y Renato Treves, Formalismo giuridico e realtá sociale, preparado por Stanley L. Paulson y aparecido en Edizioni Scientifiche Italiane, Napolés, 1992, en la ya citada y ya tan prestigiada colección «Diritto e Cultura»-de idéntico título, obsérvese, que la obra de Treves de 1947- que dirige el prof. Agostino Carrino, traductor asimismo de ella al italiano y autor, bien conocido, de valiosas publicaciones sobre el pensamiento del maestro vienés; en dicho volumen conjunto, con trabajos de ambos, se publica asimismo la extensa y laudatoria carta que Kelsen le escribiera a Treves en 1933, puntualizando sobre aspectos centrales de su teoría pura del Derecho a propósito de las observaciones críticas hechas por éste.

${ }^{11}$ Véanse, con todo (para esa preocupación y conexión), sus Lezioni di Filosofia del Diritto, Milán, Cisalpino-Goliardica, 1. ${ }^{\text {a }}$ ed. 1959-1960; 2. ${ }^{\mathrm{a}}$ ed. 1968-1969. Sobre esas preferentes dedicaciones de aquél y sus aportaciones en ellas, siempre con continuidad, está el libro de Aristide Tanzi, Renato Treves: Dalla filosofia alla sociologia del diritto, Nápoles, Edizioni Scientifiche Italiane, 1988. Para la revisión general del pensamiento de Treves, confróntese, además de los trabajos de otros autores citados en estas notas, su bibliografía de 162 títulos (hasta sólo 1983), preparada por las muy cercanas colaboradoras que fueron Nella Gridelli Velicogna y Vera Segre y que figura al final de la obra colectiva Societá, norme e valori. Studi in onore di Renato Treves, con nota preliminar y coordinación de Uberto Scarpelli y Vincenzo Tomeo, publicada por Giuffreé Ed., Milán, 1984. 
Habrá en su día que reflexionar, o que seguir reflexionando, con más detenimiento y atención sobre los resultados que para el conocimiento real del Derecho y sus progresivas transformaciones -sobre la base de cambios económicos, sociales, políticos, tecnológicosha podido suponer la Sociología jurídica durante todas estas últimas décadas, en las cuales la presencia también internacional de Renato Treves ha sido incuestionable. E, inversamente (como es aún el caso de España, contando incluso con los pasos decisivos que también en este área se han dado desde la instauración de la democracia), los déficits que su no institucionalización universitaria y escasa investigación dentro y fuera de la academia han impedido todavía superar ${ }^{12}$.

Pero téngase muy en cuenta la insistencia de Treves en que las investigaciones empíricas han de ser siempre comprendidas desde y para una sociología teórica y crítica. De ahí que, junto a la anterior reflexión, sea también imprescindible en la actual Filosofía y Sociología del Derecho la consideración, entre otras cosas, de las muy importantes relaciones e influencias que en las construcciones científico-jurídicas sobre la validez (y la legalidad / constitucionalidad) e, incluso en otra dimensión, en las filosófico-jurídicas sobre la legitimidad (y la justicia / justificación) cabe atribuir, con diferente grado y tipo de condicionalidad, a las mediaciones provenientes de la legitimación. La revista «Sociologia del Diritto», dirigida por Treves desde su fundación en 1974, con Vincenzo Ferrari como codirector y continuador, aloja ingente cantidad y cualidad de materiales, trabajos e investigaciones de gran utilidad para esas y otras tareas y reconstrucciones. Como también, al igual que en los escritos personales de aquél, y más

${ }^{12}$ Sabido es que dentro de la actual reforma universitaria española la Sociología jurídica se ha introducido finalmente, bien sea que con carácter de asignatura optativa, en los nuevos planes de estudio de nuestras Facultades de Derecho. A la, todavía, escasez entre nosotros de investigaciones empíricas en este área ha vuelto a referirse recientemente José Juan Toharia en su artículo sobre $L a$ Sociología del Derecho en España («Saber / Leer», núm. 63, Madrid, marzo de 1993), comentario de la obra de Roger Cotterrell, Introducción a la Sociología del Derecho, versión española del Prof. Carlos Ruiz Pérez, con Prólogo del Prof. Antonio-Enrique Pérez Luño, Barcelona, Ariel, 1991. Precisamente José Juan Toharia, para los jueces, junto con Ángel Zaragoza, para los abogados, fueron los iniciadores en nuestro país de investigaciones empíricas sociológico-jurídicas proseguidas en parte por el primero y que sólo han tenido después débil continuidad: añádanse a ellas algunas otras investigaciones posteriores por él allí recordadas; y también, en algún momento, con propósitos de ayuda del propio Renato Treves, las emprendidas por el «Laboratorio de Sociología Jurídica» de San Sebastián y el «Anuario Vasco de Sociología del Derecho», dirigidos por el Prof. Francisco Javier Caballero Harriet. 
allá de todo lo anterior, para aportaciones en áreas temáticas como la sociología del conocimiento, la metodología de las ciencias sociales, la relación hechos-valores, datos empíricos-teoría crítica, Derecho-cultura, por las que, desde su Filosofía y Sociología jurídica, Treves tuvo siempre una especial preocupación. La no clausura formalista del mundo jurídico, su no reduccionismo interiorista, su no fraccionamiento dentro de una realidad hoy a su vez tan escindida, así como sus contrapuntos en una filosofía y sociología crítica, me parece que pueden recibir muy valiosos estímulos a través de los esfuerzos teóricos y prácticos llevados a cabo durante toda su vida por el catedrático de la Universidad de Milán ${ }^{13}$.

${ }^{13}$ Es desde esa perspectiva de filosofía y sociología crítica desde la que, como ya he recordado en otras varias ocasiones, Treves hizo lo imposible por potenciar la Sociología del Derecho en España y por incorporarla al contexto europeo e internacional: reenvío sobre ello a los abundantes datos, también en relación con la nota anterior, que van en mi libro Sociología y Filosofía del Derecho (1971, 2. ${ }^{a}$ ed., 1980, págs. 165-172). Hasta esos mismos años y desde sus inicios krausistas se refiere la monografia de Thomas Knöpfel, Entwicklung und gegenwärtiger Stand der Rechtssoziologie in Spanien. Eine krïtische Übersicht, Berlín, Duncker und Humblot, 1982. Con posterioridad habría sin duda que destacar la creación en 1989, en gran medida por impulso del Prof. Renato Treves y bajo los auspicios del Gobierno Vasco, del «Instituto de Sociología Jurídica» con sede en Oñati (Guipúzcoa), del cual el Prof. André-Jean Arnaud ha sido su primer Director y animador permanente; en ese tiempo Treves fue nombrado Doctor «Honoris Causa» por la Universidad de San Sebastián. Sobre actividades y publicaciones llevadas a cabo en dicho Instituto, así como acerca de otros congresos, reuniones y trabajos habidos en otros ámbitos, véanse los valiosos, siempre incisivos y polémicos, escritos del profesor Roberto Bergalli, Por una Sociología jurídica en España, presentación a la obra colectiva por él coordinada El Derecho y sus realidades. Investigación y enseñanza de la Sociología Jurídica, Homenaje al Prof. Dr. Renato Treves (Barcelona, Promociones y Publicaciones Universitarias, 1989) y Sociología Jurídica en España: más frustraciones que esperanzas, presentación a la obra colectiva también por él coordinada Sentido y razón del Derecho. Enfoques socio-jurídicos para la sociedad democrática (Barcelona, Ed. Hacer, 1992); en esta obra está también, con informaciones y observaciones necesarias, el trabajo de Manuel Atienza y Juan Antonio Pérez Lledó, La Sociología del Derecho española en la actualidad (págs. 313-328). Una excelente y muy oportuna culminación del reconocimiento universitario español a la tarea llevada a cabo por el Prof. Renato Treves fue, bien merece resaltarse su investidura como Doctor «Honoris Causa» por la Universidad Carlos III de Madrid en un solemne acto académico celebrado el día 29 de enero de 1991, con «laudatio» del Prof. Eusebio Fernández, bajo la presidencia del Rector Gregorio Peces Barba. Éste fue -no lo sabíamossu último viaje, la postrer visita de Treves a España. Tampoco sabíamos que como prolongación y constancia escrita de ese reconocimiento, el núm. 1 (febrero-octubre 1993) de «Derechos y libertades» (Revista del Instituto Bartolomé de las Casas, de la Universidad Carlos III), que dirige el Prof. Gregorio Peces Barba iba a abrirse dolorosamente con un In memoriam: Renato Treves, donde junto al texto de éste 
De nuevo Norberto Bobbio, en otro muy reciente y breve escrito también de 1992, con ocasión de la muerte de aquél, tras volver a insistir en que «al menos en dos campos, la difusión del pensamiento de Kelsen y la sociología del derecho, su contribución ha sido -dice- fundamental», termina evocando, en estos tan azarosos y desmoralizantes tiempos de la Italia actual, la que habría sido, en su dimensión incluso más íntima y radical, la visión o concepción del mundo de Renato Treves: «la consciencia de la muy alta dignidad de la cultura y, a la vez, la humildad frente a las grandes dificultades de su tarea, el hondo reconocimiento ante los grandes ideales de la libertad y de la justicia, especialmente respecto de las gentes que, por hacerlos realidad, más han sufrido en sus vidas personales, el profundo sentido de la amistad entendida como recíproca ofrenda de afectos y de enseñanzas de la existencia, el amor hacia la verdad nunca separado de la duda crítica, la disciplina de la mente vivificada por el abandono a los impulsos del corazón, la fuerza de las propias convicciones siempre acompañada de la tolerancia hacia los demás. Muchos de nosotros -concluye Bobbio- han visto encarnado en él, como en ningún otro, el espíritu de la amistad» ${ }^{14}$.

Treves era un hombre bueno y con ideas claras. Quizás no tan apreciado, pues, por los que simulan o necesitan creer que la maldad y la confusión -con esos rotundos nombres o con otros de más cómoda integración- son pruebas indelebles de la más profunda inteligencia y de la más realista complejidad. Pero aquella claridad nunca le llevaba a creerse en posesión de la verdad, de ninguna verdad, casi al contrario era más bien dubitativo, perspectivista y, en su modestia, constantemente autocrítico; y su bondad, en disponibilidad siempre abierta en principio a todos, y de la que más de uno abusó, no le impedía diferenciar entre las personas para esa vía hacia el afecto y la verdadera amistad. Era suave en la forma, siempre con austera sobriedad, y firme en el fondo, si bien con generosa tolerancia. Sus críticas, más a obras que a personas (aunque unía unas a otras), siempre comenzaban por la propia autocrítica, consciente de los límites respecto de sus personales posibilidades así como, con toda honradez, hacia las posibles lagunas e

sobre Derechos del hombre, democracia y paz, se publica el artículo ya citado aquí (nota 4) de Vincenzo Ferrari, ambos en traducción de Andrea Greppi, y una breve Biografía del Prof. Renato Treves, firmada por María José Fariñas.

${ }^{14}$ Norberto Bobbio, Renato Treves, en el volumen de «Sociologia del Diritto» (XIX, 1992, 2) en que se da noticia de su muerte, págs. 7-9. 
insuficiencias de sus obras y trabajos ${ }^{15}$.

${ }^{15}$ En su muy concienzudo e incisivo Recuerdo de Renato Treves (1907- 
Vi -voy a terminar- a Renato Treves por última vez en Milán muy pocas semanas antes de su muerte, con ocasión de mi participación en una mesa redonda y una posterior conferencia sobre cultura y política española en la transición desde el franquismo a la democracia, los días 17 y 18 de marzo de 1992, actos ambos en torno a los cuales aquél -todavía controlando con gran esfuerzo y ánimo el proceso fatal de su irreversible enfermedad- tuvo una muy destacada intervención. La mesa redonda se celebró en la impresionante sede de la Biblioteca Braidense milanesa, en via Brera, y en ella tomamos parte, además de la directora de la casa que amablemente nos acogía, Antonio Elorza y yo, por parte española, con la profesora Donatella Montalto y el propio Renato Treves entre los italianos. Esa presencia suya allí resultó ser todo un símbolo de su trayectoria y biografía personal, siempre tan vinculada a nuestro país: me parece que muy probablemente la grata sesión de trabajo de aquella tarde en la que todos acabamos hablando distendidamente de la cultura y la política en la España de ayer y de hoy fue el último acto público en que ya Renato Treves pudo estar presente e intervenir. Pero le observé -recuerdo- al salir, via Brera abajo, del brazo de su mujer, bastante cansado ya tras el desgaste de esas horas de ponencias y coloquios, deseando regresar a casa...

Todavía al día siguiente tuve, sin embargo, la fortuna de poder pasar con él allí -en via Lusardi- algunos largos ratos antes y después de acudir para dar mi conferencia a la Facultad de Ciencias Políticas donde había sido invitado por los profesores Ettore A. Albertoni y Donatella Montalto. Por la tarde, a primera hora, hablamos los dos solos, con mi certeza de que él ya sabía de su próximo fin: me tenía guardados como sorpresa los primeros ejemplares de la traducción italiana, tan cuidada por Morris L. Ghezzi, de mi Ética contra política, me regaló separatas y libros suyos, algunos viejos como Derecho y cultura, otros de recientísima nueva edición como el de la mencionada recopilación conjunta con Kelsen; aunque estaba triste, se le veía feliz con él y me lo dedicó con letra, noto ahora, titubeante e indecisa incluso al escribir su propio nombre. Por la noche, tras mi conferencia, nos reunimos con él y con Fiamma en una cena en su casa con buenos

1992): líneas fundamentales de su pensamiento jurídico y político («Sistema», núm. 112, enero de 1993, págs. 117-127), hace muy bien Julián Sauquillo en resaltar, a propósito de la personalidad y los escritos de aquél, que «cuando se trata de obras comprometidas con un siglo (¿y cuál que sea verdadera obra de interés no lo es o no lo debe de ser?, anotaría yo) -con el permiso (ironiza aquél) de la "nueva crítica"- no cabe escindir autor y obra sino atender a las condiciones histórico-políticas que la alentó» (pág. 123). 
amigos y discípulos suyos, entre otros (recuerdo ahora) Mario Cattaneo, Ettore Albertoni, Mario Losano, Agostino Carrino, Donatella Montalto, Morris Ghezzi, su hijo Tulio Treves... Al principio estaba como algo ausente y más bien silencioso pero después, poco a poco, fue entrando en las conversaciones y debates y acabó, aunque era ya alta noche, muy animado y creo que hasta disfrutando y medio olvidándose de lo que todos, sin embargo, teníamos «in mente» sin podérnoslo sacar del todo en ningún momento.

Deambulé por el viejo Milán esa fría noche de marzo, tras un grande y largo abrazo final con él -los dos sabíamos que ya no nos volveríamos a ver (aunque hasta el 31 de mayo todavía habríamos de hablar por teléfono alguna vez)- evocando en soledad muchas de las cosas que ahora en estas páginas dejo escritas, en comunidad, para recuerdo y memoria de quien fue, y es, maestro y, sobre todo, amigo, casi como un buen padre, Renato Treves. 